12 Norton AJ, Ramsay AD, Smith SH, Beverley PCL, Isaacson PG. Monoclonal antibody (UCHLI) that recognises normal and neoplastic $T$ cells in routinely fixed tissues. $\mathcal{F}$ Clin Pathol
1986;39:399-405.

13 West KP, Warford A, Fray L, Campbell AC, Lauder I. Detection of B cell, T cell and myeloid antigens in peraffin section. $\mathcal{F}$ Pathol 1986;148:123A.

14 Schwab U, Stein H, Gerdes J, et al. Production of monoclonal antibody specific for Hodgkin and Reed-Sternberg cells in Hodgkin's lymphoma and a subset of normal lymphoid cells. Nature 1982;299:65-7.

15 Sheibani K, Battifora H, Burke JS, Rappaport H. Leu Ml antigen in human neoplasms. An immunohistochemical study of 400 cases. Am $\mathcal{F}$ Surg Pathol 1986;10:227-36.

16 Jack AS, Cunningham D, Soukop M, Liddle CN, Lee FD. Use of Leu M1 and anti-epithelia membrane antigen monoclonal antibodies for diagnosing Hodgkin's disease. 7 Clin Pathol 1986;39:267-70.

17 Hyder DM, Schnitzer B. Utility of Leu M1 monoclonal antibody in the differential diagnosis of Hodgkin's disease. Arch Pathol Lab Med 1986;110:416-9.

18 Stein H, Mason DY, Gerdes J, et al. The expression of the Hodgkin's disease associated antigen $\mathrm{Ki}-1$ in reactive and neoplastic lymphoid tissue: evidence that Reed-Sterberg cells and $\mathrm{K} 1-1$ in reactive and neoplastic lymphoid tissue: evidence that Reed-Sterberg cells
histiocytic malignancies are derived from activated lymphoid cells. Blood 1985;66:848-58.

19 Timen W, Visser L, Popemma S. Nodular lymphocyte predominance type of Hodgkin's disease is a germinal center lymphoma. Lab Invest 1986;54:457-61.

20 Warnke RA, Rouse RV. Limitations encountered in the application of tissue section immunodiagnosis to the study of lymphomas and related disorders. Hum Pathol 1985;16:326-31.

21 Clark DM, Boylston AW, Hall PA, Carrel S. Antibodies to T cell antigen receptor beta chain families detect monoclonal T cell proliferation. Lancet 1986;ii:835-7.

22 Shepherd NA, Blackshaw AJ, Hall PA, et al. Malignant lymphoma with eosinophilia of the gastrointestinal tract. Histopathology (in press).

\section{Reproduction and work}

The effects of work on reproductive health are attracting increasing attention because more women are working through conception and pregnancy. In addition, the harm that may be done to the reproductive health of men has been more widely recognised in the past 20 years. ${ }^{1-3}$ Those factors that are suspected of impairing reproductive function in men or women may affect either reproductive or sexual functioning of the adult fetal development at any stage after implantation.

Attributing effects on male libido and potency to work hazards is difficult: the allegations are hard to substantiate and impossible to disprove, and the range of "normal" is ill defined. Nevertheless, occupational physicians should not ignore these problems, and there has been an unsurprising (but also unproved) report of loss of libido among men working in a plant manufacturing oestrogens. Four hazards - ionising radiation, lead, ethylene oxide, and dibromochloropropane-are regulated in the United States partly because of their effects on reproduction, ${ }^{4}$ and they, and possibly others, might harm the male gametes, particularly as these are being formed continuously throughout reproductive life. Recently, the wives of men working at a factory manufacturing dibromochloropropane were finding trouble in conceiving. Subsequently, semen samples from the men were found to be grossly abnormal ${ }^{2}$ and the pesticide was banned. Though the effects of ionising radiation are well known, ${ }^{5}$ those of lead are less well defined. Studies reported from the nineteenth and the earlier part of this century were not always controlled and related to heavy exposure, which is not now seen; the results of recent studies have been more equivocal. ${ }^{67}$ Good evidence of the effects of other mutagens is lacking, and, for example, claims of reproductive problems among wives of anaesthetists remain to be substantiated. ${ }^{18}$

Reproductive toxicology in women is more complex. Showing that menstrual irregularities are specifically caused by work is difficult. Further, how can anybody be sure that a spontaneous abortion or fetal abnormality is the consequence of a development hazard encountered at work and would not have arisen spontaneously, bearing in mind that there is a natural high rate of embryo loss? ${ }^{9}$ Because a woman enters reproductive life with her full quota of gametes she may be less vulnerable than a man to hazards from mutagens. The first reduction division begins, however, in the fetus, the oocyte remaining in arrested meiotic division until some weeks before ovulation, and the second reduction division is completed about the time of fertilisation. It is in the six or seven weeks before ovulation that the oocytes are most sensitive to genetic injury, and at this time the mutation rate from irradiation increases sharply. ${ }^{10}$ In a recent study of nurses working with antineoplastic drugs those who were exposed during the first trimester had a statistically significant increase in fetal loss, but cumulative exposure was not associated with this. ${ }^{11}$

The role of occupational medicine extends beyond detecting and defining reproductive and developmental hazards to looking for a dose response relationship. That must be followed in a particular case by assessing exposure and attempting risk assessment. The problem is compounded by the many non-occupational hazards to reproduction, including drugs (iatrogenic and illicit), infectious agents, and lifestyle-for example, smoking and drinking alcohol.

How much should an employer do to make sure that the reproductive health of his workers is not harmed? The deontological approach ("Can you be sure that the conditions are quite safe for all my members, doctor?") is that he has a fundamental duty to protect the health of all his workers without exception; and working conditions must be improved so that they are safe for everyone, including pregnant women. Utilitarians would argue, however, that expenditure on reducing risk may benefit the whole community and include economic as well as technical considerations. ("Of course, we make sure that the conditions for our workers are safe so far as is reasonably practicable.") Furthermore, the same ethical argument could be used to deny access of the more susceptible groups among the workforce, including pregnant women, to environments that may harm their health. Indeed, such reasoning forms the philosophical basis for much pre-employment screening. ${ }^{12}$

Excluding susceptible groups would probably mean excluding all women of reproductive age because of the difficulty in confidently recognising early pregnancy. Should there be monitoring for pregnancy or voluntary removal policies if pregnancy is contemplated without prejudice to salary or career development? Should there be sex discrimination policies in high risk occupations? These proposals immediately run into serious difficulties. They may be seen by some workers as an intrusion into their privacy, and none of these methods of protection (other than sex discrimination) will cater for the unplanned and unforeseen pregnancy. Another twist occurs because women have been discriminated against and we now have legislation to ensure equal opportunities. How may that be reconciled with "discriminatory" measures aimed to protect another party, the fetus?

A range of compromises, from a sex based exclusion policy through to voluntary removal after personal and medical counselling, will emerge. Doctors, long since accustomed to being ones from whom no secrets are hid, would now be proposing themselves as one to whom all desires are made known.

W R LEE

Professor of Occupational Health,

University of Manchester,

Manchester M13 9PT

Elizabeth C McCloy

Occupational Physician,

Manchester Royal Infirmary,

Manchester M13 9WL 
1 Knill-Jones RP, Newman BJ, Spence AA. Anaesthetic practice and pregnancy. Lancet 1975;ii: $807-9$.

2 Whorton D, Krauss RM, Marshall S, Milby TH. Infertility in male pesticide workers. Lancet 1977;ii: 1259-61.

3 Berlin M, Lee IP, Russell LD Effects of metals on male reproduction. In: Clarkson TW, Nordberg GF, Sager PR, eds. Reproductive and developmental toxicity of metals. London: Plenum Press, 1983:29-40.

4 United States Congress Office of Technology Assessment. Reproductive health hazards in the workplace. Washington DC: US Government Printing Office, 1985:4

5 Mettler FA, Moseley RD. Medical effects of ionizing radiation. Orlando: Grune and Stratton, 1985: $159-60$.

6 Sullivan FM, Barlow SM. Congenital malformations and other reproductive hazards from environmental chemicals. Proc $R$ Soc Lond [Biol] 1979;205:91-110.

7 Thomas JA, Brogan WC. Some actions of lead on the sperm and on the male reproductive system. Am $\mathcal{F}$ Ind Med 1983;4:127-34.

8 Tannenbaum TN, Goldberg RJ. Exposure to anaesthetic gases and reproductive outcome. $\mathcal{F}$ Tannenbaum TN, Goldberg
Occup Med 1985;27:659-68.

Miller JF, Williamson E, Glue J, Gordon YB, Grudzinskas JG, Sykes A. Fetal loss after Miller JF, Williamson E, Glue J, Gordon YB, Grudzinsk
implantation-a prospective study. Lancet 1980;ii:554-6.

10 Russell JGB. The rise and fall of the ten-day rule. Br f Radiol 1986;59:3-6.

11 Selevan SG, Lindbohm ML, Hornung RW, Hemminki K. A study of occupational exposure to antineoplastic drugs and fetal loss in nurses. $N$ Engl f Med 1985;313:1173-8.

12 Lee WR. What should we do about work related cancer? Br Med f 1986;292:1155-6.

\section{Man bites dog}

"When a dog bites a man that is not news, but when a man bites a dog that is news" - and recently a man did just that. ${ }^{1}$ But man also seems to be increasingly likely to bite man, and human bites in New York City rank third after dog and cat bites, with an annual incidence of $12 / 100000$ population. ${ }^{2}$ Human bites are potentially more serious than bites from domestic animals, and about three quarters are related to aggressive behaviour (the rest are accidental). Children may be the victims, and bites are often seen on "battered children." ${ }^{3}$ Bites may occur accidentally when people are nursing psychiatrically disturbed patients, and they are an occupational hazard for dentists. They may also occur during sporting or sexual activity.

Two thirds of bites are on the arms, with half of these being on the hands. ${ }^{2}$ Hand bite wounds can be separated into two main types: straightforward bite wounds and the more serious clenched fist injuries that occur when an individual punches another's teeth with a closed fist. The teeth may enter skin and penetrate the extensor tendon, joint capsule, and the metacarpophalangeal joint, damaging the articular surfaces. The patient may well present with what appears to be an innocuous skin wound because the fingers are held in extension-the skin and tendon wounds are thus no longer adjacent and the full extent of the injury is masked. The doctor may miss this injury with disastrous consequences for later hand function. Delay of 12 hours or more in obtaining treatment for penetrating injuries leads to a $60 \%$ complication rate. ${ }^{4}$

Human bites appear to have a greater potential for causing deep necrotising infection than animal bites. ${ }^{5} 6$ The severity may vary with dental hygiene; bacterial counts from even healthy mouths are high, but they have more aerobic flora than mouths of people with poor dental hygiene. Bites from children seem less hazardous-perhaps because they have more aerobic flora. ${ }^{7}$

Goldstein et al looked at 34 patients with human bites, 16 of which were clenched fist injuries. ${ }^{8}$ When first seen all the clenched fist injuries and eight of the 18 simple bites appeared infected: 33 of the 34 patients had aerobic or facultative pathogens isolated, and 18 also had anaerobes. $\alpha$ Haemolytic streptococci followed by coagulase negative staphylococci, Corynebacterium spp, Staphylococcus aureus, and group A streptococci were the most frequent isolates. Bacteroides spp (especially Bacteroides melaninogenicus) were the most common isolated anaerobes. Group A streptococci, $S$ aureus, and Eikenella corrodens were usually associated with infection. Other workers have reported the frequent isolation of penicillin resistant Gram negative organisms, , but Goldstein et al found few.

$S$ aureus has been isolated in up to four fifths of infections caused by human bites in some series ${ }^{10}$ and is often associated with severe infections and complications. ${ }^{4}$ Mann et al found that half of human bites that had a poor outcome had been infected with $S$ aureus. ${ }^{7}$

In one series $E$ corrodens was isolated from $29 \%$ of human bites. ${ }^{11}$ There has been debate over the pathogenicity of this organism in man, but Schmidt and Heckman found that pure infections were associated with long term complications, which they thought supported its pathogenic role. ${ }^{12}$

Syphilis has been reported as being transmitted by a human bite, ${ }^{13}$ and hepatitis $B$ virus may also be transmitted, ${ }^{14-16}$ which is a problem for those caring for the mentally handicapped. Human immunodeficiency virus has been isolated from saliva, ${ }^{17}{ }^{18}$ but there is as yet no substantial evidence to show that it can be spread by biting.

We believe that in managing human bites an aggressive approach is necessary and delay dangerous. Inpatient treatment is usually needed. Generally early exploration of wounds to determine the extent of damage with irrigation and any necessary debridement is important and elevation of the hand helpful. Taylor agrees that only those who present very early with scratches and abrasions can afford to be treated without surgical intervention. ${ }^{19}$ Patients who present without signs of infection with an undetected joint or tendon injury may later develop sesptic complications despite being given what seems adequate antibiotic treatment, which illustrates the importance of wound exploration. Clenched fist injuries must be regarded as infected, and after taking specimens for culture the doctor should start antibiotics immediately. Broad spectrum antibiotics are necessary until the culture and sensitivity reports are available.

Most anaerobic Gram negative rods of the oral flora are penicillin sensitive, and so treatment with penicillin plus a penicillinase resistant penicillin (such as cloxacillin) to cover $S$ aureus is satisfactory. ${ }^{19}{ }^{20}$ Some, however, recommend using flucloxacillin or a cephalosporin alone pending the results of culture. ${ }^{6}{ }^{10}$ Taylor suggested using cephalosporins or erythromycin for patients allergic to penicillin ${ }^{19}$; he did not note any reactions to cephalosporins in his patients. Those who have found a high percentage of Gram negative organisms in human bite wounds recommend using penicillinase resistant penicillin with an aminoglycoside. ${ }^{7}$ Others consider penicillin resistant Gram negative bacilli to be uncommon and treat them only when results of culture are available..$^{20}$ Clostridium tetani is rare in human bites, ${ }^{21}$ but tetanus prophylaxis is provided by many doctors and is still probably desirable. $^{10} 19$

Despite adequate initial treatment complications may still occur. Loss of function, joint stiffness, septic arthritis, osteomyelitis, or tenosynovitis may result from what appeared a trivial injury. Even septicaemia and death, although rare, have occurred. Human bites must never be considered trivial, and accurate diagnosis and treatment must be the aim.

B KIRKPATRICK Registrar in microbiology R WISE

Department of Medical Microbiology,

Consultant and reader

Dudley Road Hospital,

Birmingham B18 7QH 